\title{
Simulation of the noise of domestic appliances using the CadnaA programme
}

\author{
Raimondas Grubliauskas, Žilvinas Venckus \\ Vilnius Gediminas technical university, Sauletekio av. 11, LT-10223 Vilnius, Lithuania
}

\begin{abstract}
The article deals with the importance of mathematical simulation. It explains the application of the programme CadnaA for simulating noise dispersion in closed environments. Two mathematical simulations are presented. The first simulation is a two-room apartment with the area of $44 \mathrm{~m}^{2}$; it has a kitchen, WC and bathroom (in one room) and a storage room. The second simulation is a hairdresser's salon of $40 \mathrm{~m}^{2}$ with three working spaces, WC, and a staff dining room. The simulations are performed with the frequencies of $63 \mathrm{~Hz}, 500 \mathrm{~Hz}$, and $4000 \mathrm{~Hz}$. In order to verify the correspondence of results of the simulations with natural measurements, a comparative noise measurement was taken in an apartment matching the first simulation. Measurement results were compared with the model and presented in the article.
\end{abstract}

Keywords: domestic appliances; noise; modeling; CadnaA.

\section{Introduction}

A contemporary person is accompanied by noise everywhere. A tired person goes home after work by noisy streets. He switches on a fan or TV at home. At the same time he is cooking dinner using a mixer or blender, cooker hood, and other appliances. After cooking, the dishwasher is switched on. Thus, the sound of various appliances joins into a general noise (American Speech... 2011).

The evolution of domestic appliances was particularly significant in the last decades. The capacity of appliances is being constantly increased, the consumption of energy is being reduced, the selection of appliances is rapidly increasing, and the demand and supply are growing (Dries 2009).

A simulation is the research of the processes and constructions that are inconvenient to study under natural conditions using their models or the research of the peculiarities of a phenomenon by studying the peculiarities of an identical phenomenon. Numerical or mathematical simulation is the numerical or analytical solution of the researched process or phenomenon, described by differential equations and restricted by the terms of unambiguousness, i.e. creating and implementing a mathematical model, finding a solution to a task (Petraitis 2010. Strategic maps of noise were created as the result of simulation of noise dispersion. Strategic maps of noise are intended for generalised assessment of the effect of various sources of noise in a particular area or for presenting a generalised forecast (2002/49/EB).

Computer programme CadnaA (Computer Aided Noise Abatement) was used for simulating and forecasting noise dispersion. This programme is designed for simulating various scenarios selecting one or several types of sources of noise (mobile: roads, railroads, air transport; spot: industrial companies, etc.) (Grubliauskas 2009).

Simulation of noise dispersion is important for improving the acoustic condition of the environment. In order to improve the acoustics of premises, one must understand the relations between the users of the premises, sources of noise, the field of the source of noise, and the layout of the premises (Ver and Beranek 2006).

Computer simulation allows observing the dispersion of noise in space. This means is important in noise reduction projects and verification of results. However, the results of a simulation may be slightly different from actual measurements, since there are many factors affecting the measurement results in reality (Yijun et al. 2012).

The aim of the present work is to create a model of noise emitted by domestic appliances in a room using the programme CadnaA.

Corresponding author: Raimondas Grubliauskas. E-mail address: raimondas.grubliauskas@vgtu.lt

http://dx.doi.org/10.3846/enviro.2014.023

(C) 2014 The Authors. Published by VGTU Press. This is an open-access article distributed under the terms of the Creative Commons Attribution License, which permits unrestricted use, distribution, and reproduction in any medium, provided the original author and source are credited. 


\section{Methodology}

The measurements of noise emitted by domestic appliances were performed in the Department of Environment Protection of Vilnius Gediminas Technical University in a designated noise abatement chamber. To ascertain the level of noise emitted by domestic appliances, a meter-analyser of sound level Bruel\&Kjaer 2260 was used.

This meter-analyser helps to ascertain the equivalent, maximum and minimum sound level at one. It also ascertains sound levels at different frequency bands. The noise registered by the device falls in the range of frequencies from $6.3 \mathrm{~Hz}$ to $20 \mathrm{~Hz}$ in one or $1 / 3$ octave frequency bands. It allows measuring the efficient noise level defined by characteristics $\mathrm{A}, \mathrm{B}$ or $\mathrm{C}$ or in different octaves, distinguished by standardised filters. Relative measurement error of the device is $\pm 1.5 \%$.

The results of the research performed in noise abatement chamber are presented in Table 1 and Figure 1.

Table 1. Frequency characteristics of noise levels emitted by domestic appliances

\begin{tabular}{llllllllll}
\hline & $63 \mathrm{~Hz}$ & $125 \mathrm{~Hz}$ & $250 \mathrm{~Hz}$ & $500 \mathrm{~Hz}$ & $1 \mathrm{kHz}$ & $2 \mathrm{kHz}$ & $4 \mathrm{kHz}$ & $8 \mathrm{kHz}$ & $16 \mathrm{kHz}$ \\
\hline Vacuum cleaner Philips & 24 & 33 & 53 & 66 & 76 & 74 & 69 & 60 & 52 \\
Hairdryer Effectus & 21 & 24 & 31 & 47 & 59 & 60 & 59 & 52 & 40 \\
Hairdryer Gamma & 14 & 23 & 44 & 53 & 64 & 67 & 64 & 59 & 47 \\
Hairdryer Megaturbo & 18 & 23 & 35 & 54 & 52 & 58 & 56 & 51 & 41 \\
Safety razor Philips & 13 & 13 & 20 & 39 & 42 & 50 & 54 & 46 & 34 \\
\hline
\end{tabular}

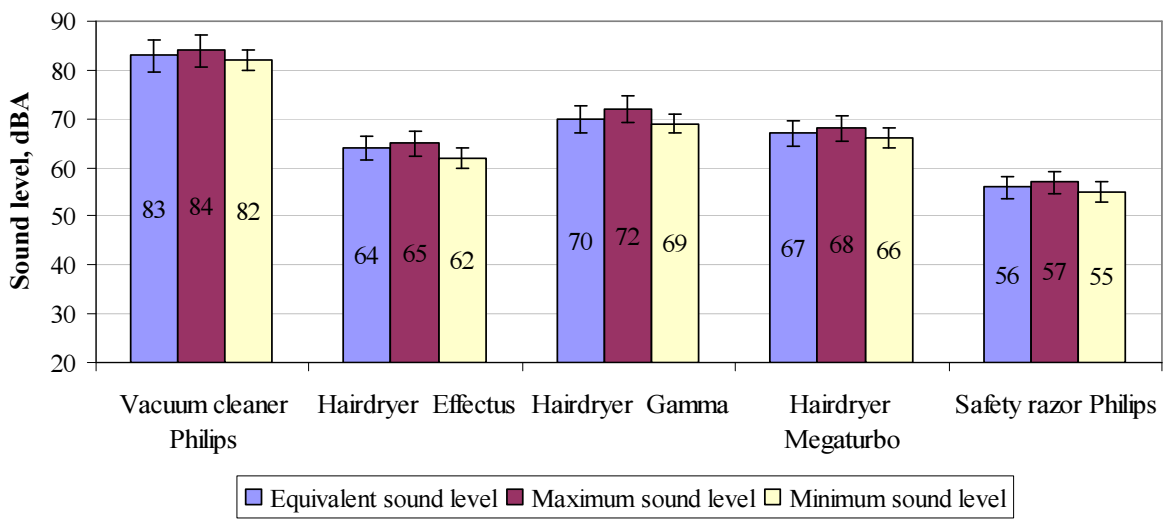

Fig. 1. Noise levels emitted by domestic appliances

Having carried out the research of noise emitted by domestic appliances, the simulation of noise dispersion was performed. The computer programme CadnaA was used for simulating noise dispersion.

In order to simulate the noise dispersion of domestic appliances, a frame depicting the room is drawn. The partitions representing the walls or other divisions of the room are marked inside the frame. A spot source of noise is marked inside the room a domestic appliance emitting the noise. The programme allows observing the dispersion of sound in the room.

When simulating a room, the following properties of a room are not taken into account: furniture, carpeting, surface of the walls, and windows.

The main parameters of a room model are the dimensions of the room. Figure 2 presents the model of a $44 \mathrm{~m}^{2}$ apartment of two rooms. The apartment has a kitchen, $\mathrm{WC}$ and bathroom (in one room), and a storage room.

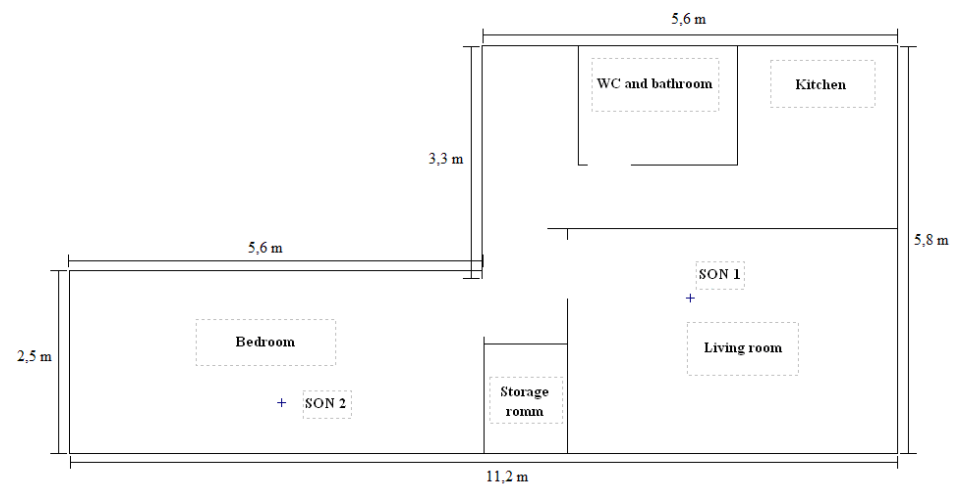

Fig. 2. Layout of rooms selected for simulation: SON1; SON2 - the sources of noise 
Having marked a spot source of noise, its parameters are selected in the editing window, i.e. the emitted noise according to frequencies and the height of the source. SON1 - vacuum cleaner Philips with the capacity of $1800 \mathrm{~W}$, equivalent sound level $83 \mathrm{dBA}$. The height of SON1 from the surface of the floor is $0.4 \mathrm{~m}$. SON2 is a hairdryer Effectus. The capacity of this source of noise is $1200 \mathrm{~W}$, equivalent sound level $64 \mathrm{dBA}$. The height of SON2 from the surface of the floor is $1.7 \mathrm{~m}$. The simulation is performed with the frequencies of $63 \mathrm{~Hz}, 500 \mathrm{~Hz}$, and $4 \mathrm{kHz}$.

The noise emitted by a spot source is dispersed spherically and decreases logarithmically as the distance to the source increases (Rahmani et al. 2010).

Having defined the calculation area, CadnaA performs the calculations for each point of emission inside the area. Since the area of the created model is relatively small, in order to obtain a sharp view, the calculation grid is densified to $0.03 \mathrm{~m}$. The height of calculating the level of noise is selected at the level of the head of an adult person $1.7 \mathrm{~m}$.

The obtained results are presented in different colours and colour combinations from light green to black.

The second model is a hairdresser's salon of $40 \mathrm{~m}^{2}$ with three working places, WC, and the staff dining room (Fig. 3).

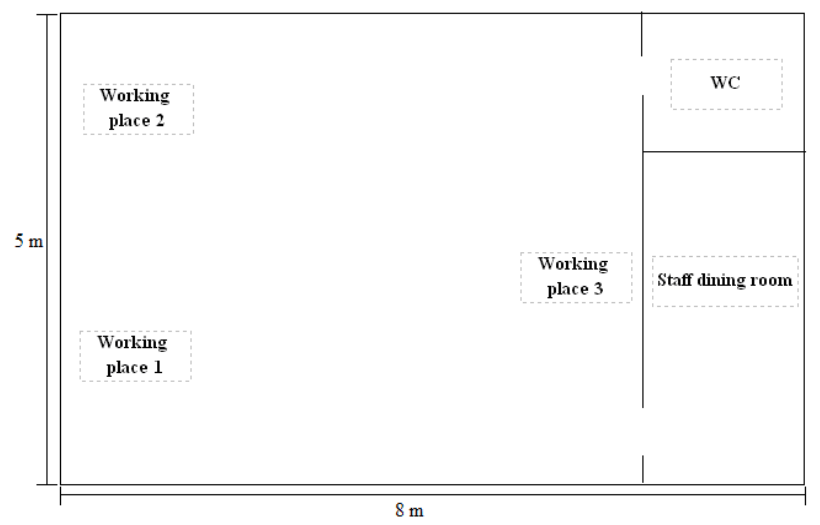

Fig. 3. Hairdresser's salon with three working places

In the second model, SON1 is the hairdryer Gamma with the capacity of $1500 \mathrm{~W}$, equivalent sound level is $70 \mathrm{dBA}$. SON2 is a hairdryer Megaturbo with the capacity of $1200 \mathrm{~W}$; equivalent sound level is 67 dBA. SON3 is a safety razor Philips with the capacity of $3 \mathrm{~W}$; equivalent sound level $56 \mathrm{dBA}$. The height from the surface of the floor of all sources of noise is $1.5 \mathrm{~m}$. The simulation is performed with the frequencies of $63 \mathrm{~Hz}, 500 \mathrm{~Hz}$, and $4 \mathrm{kHz}$.

In order to verify whether the results of the simulations correspond to natural measurements, a comparative measurement of noise was performed in an apartment equivalent to the first model. Points of measurement POM1-POM9 are presented in Figure 4.

The standard LST ISO 1996-2:2008 describes the conditions of noise measurement in enclosed environment. When measuring the noise inside a building, the microphone must be at least $0.5 \mathrm{~m}$ away from the walls, ceiling, and floor and at least $1 \mathrm{~m}$ away from the windows or vents. The distance between adjacent points of measurement must be at least $0.7 \mathrm{~m}$. The measurement must last at least 15 s (LST ISO 1996-2:2008).

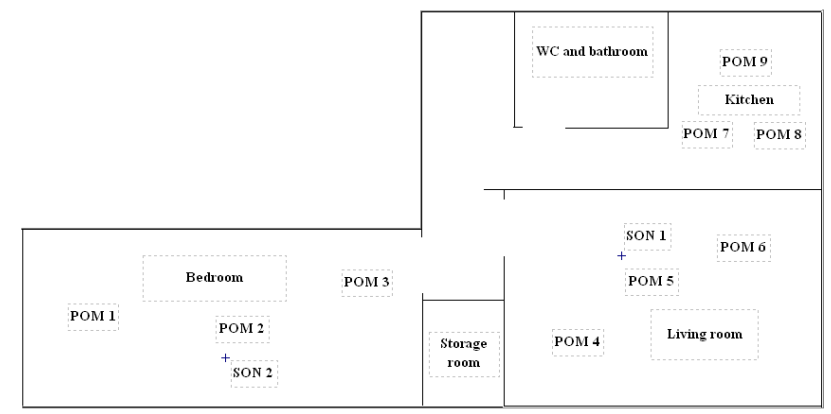

Fig. 4. Layout of the premises where natural measurements were performed:

SON1; SON2 - the sources of noise; POM1 - POM9 - points of measurement

When performing natural measurements, the requirements of standard LST ISO 1996-2:2008 were observed. The measurements were performed at the height of $1.7 \mathrm{~m}$ since it corresponds to the height of the results of the created model. The level of noise was measured for $30 \mathrm{~s} .3$ measurements of each point were taken. The measurements were performed in three points in each room. 


\section{Results and analysis}

Two models were created by the programme CadnaA to depict the dispersion of noise emitted by domestic appliances: the first model is a residential apartment of two rooms and the second one is a hairdresser's salon with three working spaces. Both models represent the dispersion of noise with the frequencies of $63 \mathrm{~Hz}, 500 \mathrm{~Hz}$, and $4 \mathrm{kHz}$. The first model is compared with natural measurements in an apartment equivalent to the model.

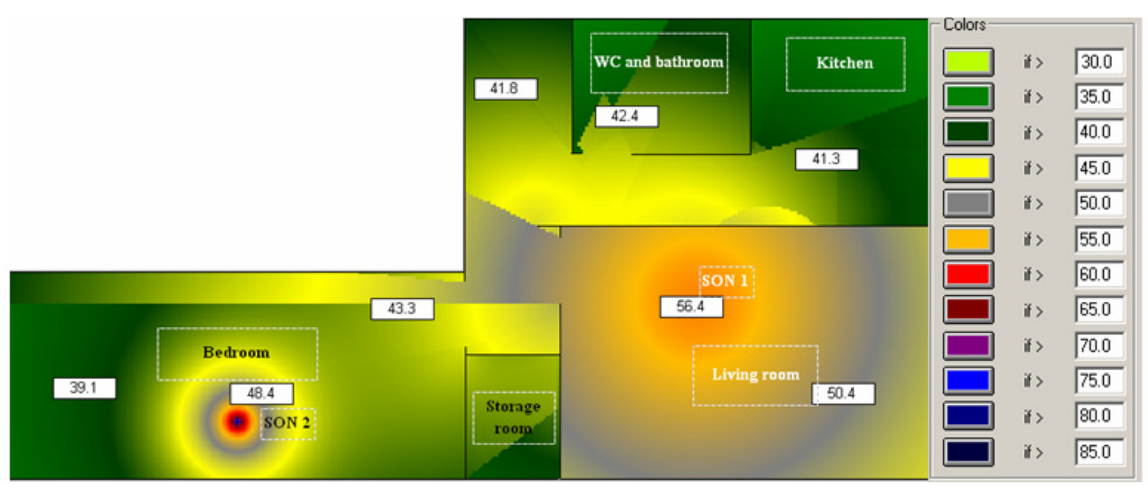

Fig. 5. Dispersion of noise in a two-room residential apartment with the frequency of $63 \mathrm{~Hz}$ : SON1 - vacuum cleaner Philips; SON2 - hairdryer Effectus

The dispersion of noise in a two-room residential apartment, where two domestic appliances are operating at the same time (vacuum cleaner Philips with the noise level of $83 \mathrm{dBA}$ and a hairdryer Effectus with the noise level of $64 \mathrm{dBA}$ ) with the frequency of $63 \mathrm{~Hz}$ is depicted in Figure 5.

In the living room, where the noisier device (the vacuum cleaner) is operating, the level of noise was the highest. Above the device, at the height of $1.7 \mathrm{~m}$, the level of noise was $56 \mathrm{dBA}$. In the other parts of the living room, farther away from the source of noise, the sound level variates between $48 \mathrm{dBA}$ and $55 \mathrm{dBA}$.

Noise levels in the kitchen variates between $35 \mathrm{dBA}$ (the most distant point from the SON1) and 42 dBA (closest to the wall separating the kitchen from the living room).

In the hallway between the living room and the bedroom, the level of noise was $50 \mathrm{dBA}$. Going to the bedroom, the noise slightly decreased and gradually faded moving away from SON1 (northern side of the bedroom). In the remaining part of the room, the levels of noise were slightly lower: from $37 \mathrm{dBA}$ to $42 \mathrm{dBA}$. The level of noise increased around SON2: it was $48 \mathrm{dBA}$ at the distance of $\sim 0.5 \mathrm{~m}$ around the device and up to $77 \mathrm{dBA}$ above SON2. Above SON2, the level of noise was higher than emitted by the appliance itself due to the influence of SON1 (the levels of noise of both devices added up).

The dispersion of noise with the frequency of $500 \mathrm{~Hz}$ in a two-room apartment, where two domestic appliances are operating at the same time (vacuum cleaner Philips with the equivalent sound level of $83 \mathrm{dBA}$ and a hairdryer Effectus with the equivalent sound level of $64 \mathrm{dBA}$ ) is depicted in Fig. 6.

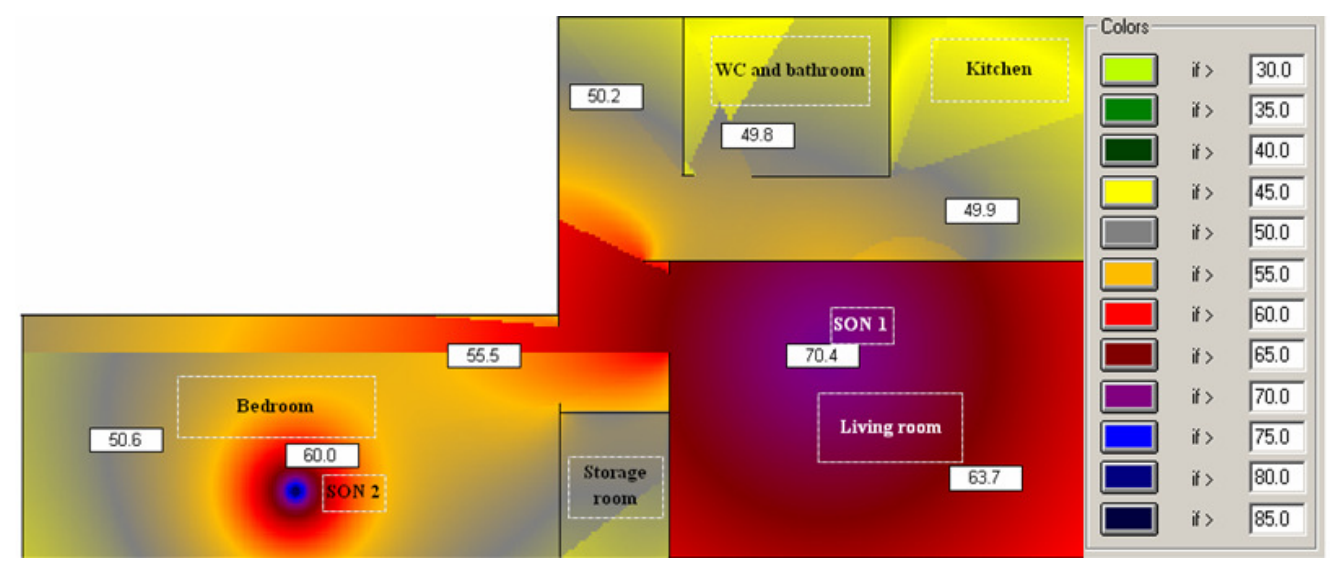

Fig. 6. Dispersion of noise in a two-room residential apartment with the frequency of $500 \mathrm{~Hz}$ : SON1 - vacuum cleaner Philips; SON2 - hairdryer Effectus

In the living room, where SON1 is operating, the level of noise was the highest. Above the device, at the height of $1.7 \mathrm{~m}$, the level of noise was $70 \mathrm{dBA}$. The level of noise exceeded $60 \mathrm{dBA}$ in the entire living room.

In the kitchen, the level of noise variates between $45 \mathrm{dBA}$ (at the most distant point from SON1) to $50 \mathrm{dBA}$ (closest to the wall separating the kitchen from the living room). 
In the hallway between the living room and the bedroom, the level of noise exceeded $60 \mathrm{dBA}$. In the bedroom, the level of noise variates between $48 \mathrm{dBA}$ and $55 \mathrm{dBA}$. Around SON2, the level of noise increased: it was from $58 \mathrm{dBA}$ at the distance of $\sim 0.5 \mathrm{~m}$ around the device up to $84 \mathrm{dBA}$ above SON2 itself.

The dispersion of noise with the frequency of $4 \mathrm{kHz}$ in a two-room apartment, where two domestic appliances are operating at the same time (vacuum cleaner Philips with the equivalent sound level of $83 \mathrm{dBA}$ and a hairdryer Effectus with the equivalent sound level of $64 \mathrm{dBA}$ ) is depicted in Fig. 7.

In the living room above SON1 the level of noise was $70 \mathrm{dBA}$. The level of noise exceeded $60 \mathrm{dBA}$ in the entire living room.

In the kitchen, the level of noise variates between $39 \mathrm{dBA}$ (at the most distant point from SON1) to 45 dBA (closest to the wall separating the kitchen from the living room).

In the hallway between the living room and the bedroom, the level of noise exceeded $60 \mathrm{dBA}$. In the bedroom, the level of noise variates between $47 \mathrm{dBA}$ and $55 \mathrm{dBA}$. Around SON2, the level of noise increased: it was from $57 \mathrm{dBA}$ at the distance of $\sim 0.5 \mathrm{~m}$ around the device up to $87 \mathrm{dBA}$ above SON2 itself.

The noise emitted by both sources of noise was dispersed spherically, which is illustrated by Figures 4-6. The highest level of noise was next to the source of noise and gradually decreased moving away from it.

As seen in Figures 4-6, SON1 affects the hallway and the kitchen the most. In this space, the wall separating the living room from the kitchen is very significant for the decrease of the level of noise.

SON2 is of lower capacity and more silent and therefore, the level of noise in the bedroom is significantly lower than in the living room. The general level of noise in the bedroom is affected not only by SON2, but also by SON1, the noise of which reaches the room.

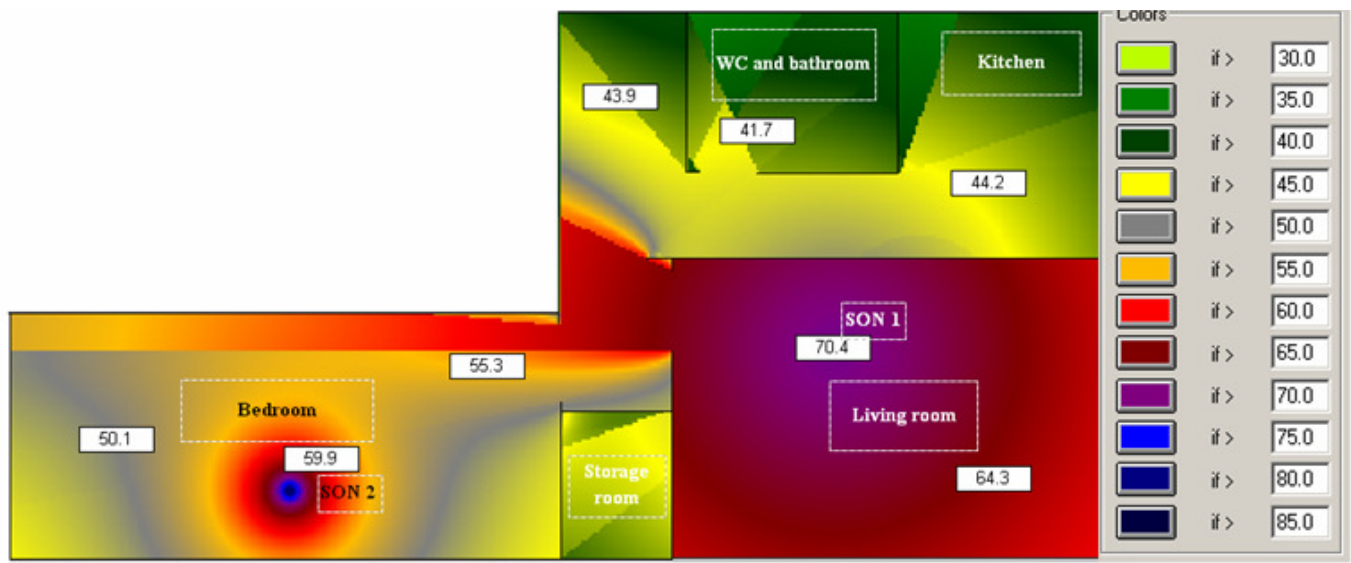

Fig. 7. Dispersion of noise in a two-room residential apartment with the frequency of $4 \mathrm{kHz}$ : SON1 - vacuum cleaner Philips; SON2 - hairdryer Effectus

With the frequency of $500 \mathrm{~Hz}$ and $4 \mathrm{kHz}$, the levels of noise are quite similar. With the frequency of $63 \mathrm{~Hz}$, the level of noise decreases significantly, since SON1 and SON2 emit less noise in low frequency band.

In the hairdresser's salon, where three domestic appliances are operating at the same time (hairdryer Gamma with the level of noise of $70 \mathrm{dBA}$, hairdryer Megaturbo with the level of noise of $67 \mathrm{dBA}$ and the safety razor Philips with the level of noise of $56 \mathrm{dBA}$ ), the dispersion of noise with the frequency of $63 \mathrm{~Hz}$ is presented in Fig. 8 .

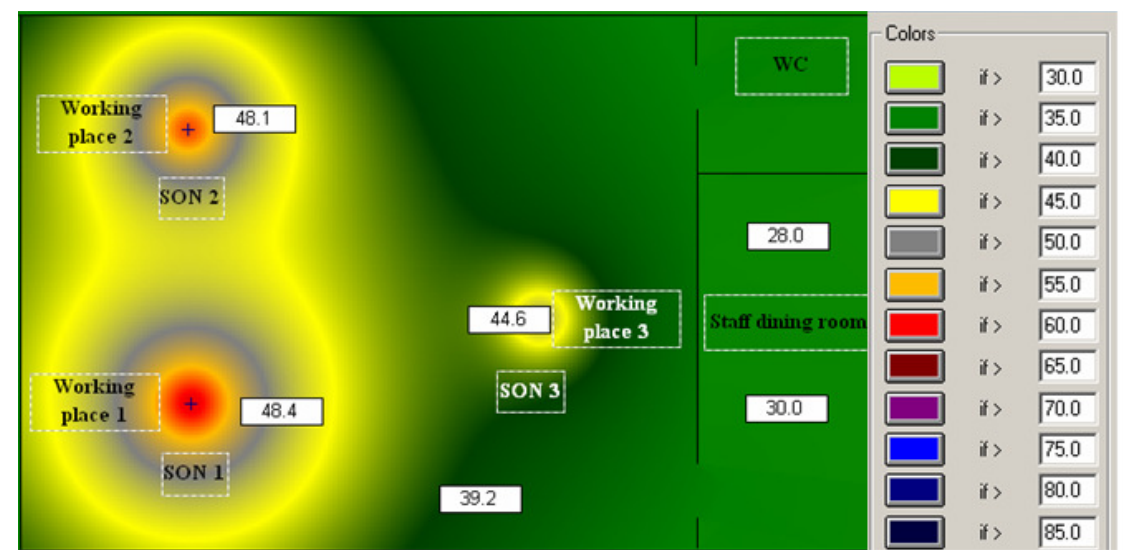

Fig. 8. Dispersion of noise in the hairdresser's salon with the frequency of $63 \mathrm{~Hz}$ : SON1 - hairdryer Gamma; SON2 - hairdryer Megaturbo, SON3 - safety razor Philips 
In the first and second working places, where noisier devices (hairdryers) are used, a higher level of noise was observed: from $48 \mathrm{dBA}$ at the distance of one meter from the sources of noise to $60 \mathrm{dBA}$ next to SON2 and $62 \mathrm{dBA}$ next to SON1.

In the third working place, the levels of noise are lower, since the device used there is more silent. Next to the SON3, the level of noise was $45 \mathrm{dBA}$. At close distance to the source of noise, the level of noise was higher. In the remaining space, where the customers are waiting, the level of noise was from $35 \mathrm{dBA}$ to $39 \mathrm{dBA}$. In the staff dining room and the WC, the sound level was up to $30 \mathrm{dBA}$.

In the hairdresser's salon, where three domestic appliances are operating at the same time (hairdryer Gamma with the level of noise of $70 \mathrm{dBA}$, hairdryer Megaturbo with the level of noise of $67 \mathrm{dBA}$ and the safety razor Philips with the level of noise of $56 \mathrm{dBA}$ ), the dispersion of noise with the frequency of $500 \mathrm{~Hz}$ is presented in Fig. 9.

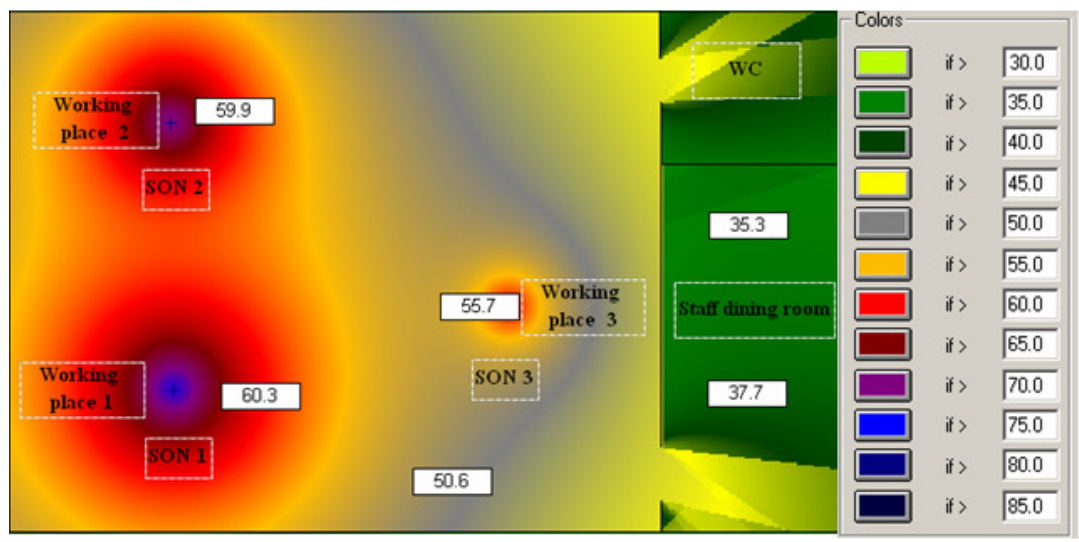

Fig. 9. Dispersion of noise in the hairdresser's salon with the frequency of $500 \mathrm{~Hz}$ : SON1 - hairdryer Gamma; SON2 - hairdryer Megaturbo, SON3 - safety razor Philips

With the frequency of $500 \mathrm{~Hz}$, the level of noise was much higher. In the first and second working place, a higher level of noise was observed: from $60 \mathrm{dBA}$ at the distance of one meter from the sources of noise to $70 \mathrm{dBA}$ next to SON2 and 73 dBA next to SON1.

In the third working place, the sound level next to the source of noise was $56 \mathrm{dBA}$. At close distance to the source of noise, the level of noise was higher. In the remaining space, where the customers are waiting, the level of noise was from 47 $\mathrm{dBA}$ to $55 \mathrm{dBA}$.

In the staff dining room and the WC, the sound level did not exceed $45 \mathrm{dBA}$.

In the hairdresser's salon, where three domestic appliances are operating at the same time (hairdryer Gamma with the level of noise of $70 \mathrm{dBA}$, hairdryer Megaturbo with the level of noise of $67 \mathrm{dBA}$ and the safety razor Philips with the level of noise of $56 \mathrm{dBA}$ ), the dispersion of noise with the frequency of $4 \mathrm{kHz}$ is presented in Fig. 10 .

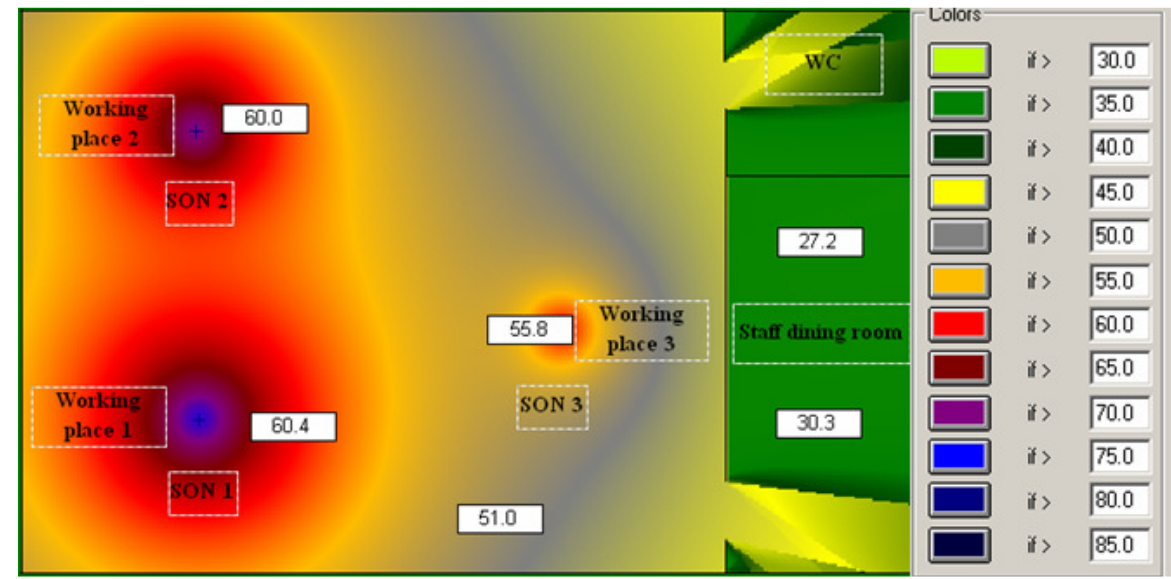

Fig. 10. Dispersion of noise in the hairdresser's salon with the frequency of $4 \mathrm{kHz}$ : SON1 - hairdryer Gamma; SON2 - hairdryer Megaturbo, SON3 - safety razor Philips

The model with the frequency of $4 \mathrm{kHz}$ is very similar to the model with $500 \mathrm{~Hz}$. In all working places, the level of noise differed by less than one decibel. Lower noise levels with the frequency of $4 \mathrm{kHz}$ were observed only in the staff dining room and the WC: the level of noise was up to $30 \mathrm{dBA}$ there.

The physicians note that the noise that is harmful to health (higher and long-lasting or interrupting the sleep) is that over 60 dBA (Nelson 2005).

According to World Health Organisation, long-lasting noise at the level exceeding 60 dBA increases the risk of myocardial infarction and ischemic heart disease (World Health... 2012). 
The level of noise of $60 \mathrm{dBA}$ is exceeded in the first model. In the living room, the level of noise was $70 \mathrm{dBA}$. Prolonged exposure to such noise may have a negative effect on health. In the second model, the noise did not exceed $60 \mathrm{dBA}$.

Having performed the mathematical simulation, the level of noise at the selected nine points in the apartment was measured using the meter-analyser of the level of noise. The points of measurement (POM1-POM9) and the noise at those points according to the simulation with the frequency of $500 \mathrm{~Hz}$ are presented in Fig. 11.

The results of natural measurements of the level of noise are presented in Tables 2-4. For the purposes of comparison, the Tables also present the results of simulation and the difference (in decibels and percent) between the model and measurement results.

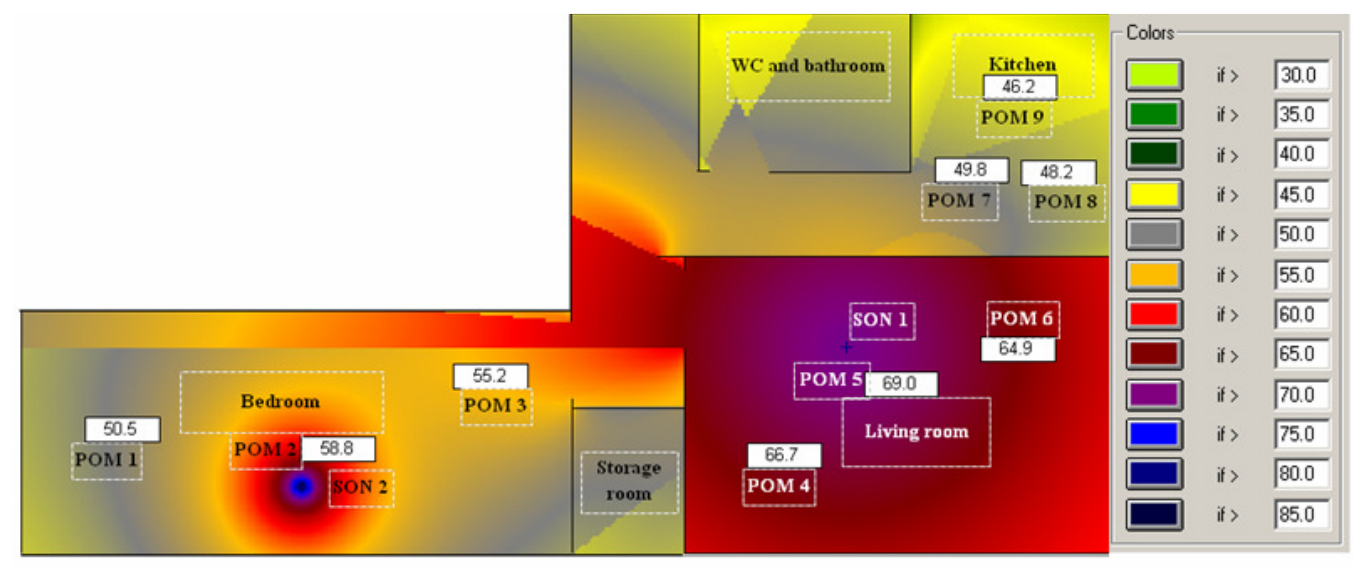

Fig. 11. Measurement points (MT 1-MT 9) of the level of noise in the apartment corresponding to the mathematical model with the frequency of $500 \mathrm{~Hz}$

Table 2. The level of noise (in decibels) obtained during simulation using the CadnaA programme and under natural conditions with the frequency of $63 \mathrm{~Hz}$

\begin{tabular}{llllllllll}
\hline & MT 1 & MT 2 & MT 3 & MT 4 & MT 5 & MT 6 & MT 7 & MT 8 & MT 9 \\
\hline Results of measurements & 40 & 49 & 48 & 55 & 56 & 56 & 41 & 41 & 40 \\
Results of simulation & 39 & 47 & 43 & 53 & 55 & 52 & 42 & 40 & 37 \\
Difference, dBA & 1 & 2 & 5 & 2 & 1 & 4 & 1 & 1 & 3 \\
Difference, \% & 3 & 4 & 10 & 4 & 2 & 7 & 2 & 2 & 8 \\
\hline
\end{tabular}

Table 3. The level of noise (in decibels) obtained during simulation using the CadnaA programme and under natural conditions with the frequency of $500 \mathrm{~Hz}$

\begin{tabular}{llllllllll}
\hline & MT 1 & MT 2 & MT 3 & MT 4 & MT 5 & MT 6 & MT 7 & MT 8 & MT 9 \\
\hline Results of measurements & 56 & 61 & 59 & 70 & 73 & 70 & 55 & 53 & 50 \\
Results of simulation & 51 & 59 & 55 & 67 & 69 & 65 & 50 & 48 & 46 \\
Difference, dBA & 5 & 2 & 4 & 3 & 4 & 5 & 5 & 5 & 4 \\
Difference, \% & 9 & 3 & 7 & 4 & 5 & 7 & 9 & 9 & 8 \\
\hline
\end{tabular}

Table 4. The level of noise (in decibels) obtained during simulation using the CadnaA programme and under natural conditions with the frequency of $4 \mathrm{kHz}$

\begin{tabular}{llllllllll}
\hline & MT 1 & MT 2 & MT 3 & MT 4 & MT 5 & MT 6 & MT 7 & MT 8 & MT 9 \\
\hline Results of measurements & 55 & 63 & 59 & 66 & 68 & 66 & 44 & 45 & 44 \\
Results of simulation & 50 & 59 & 54 & 67 & 69 & 65 & 45 & 43 & 41 \\
Difference, dBA & 5 & 4 & 5 & 1 & 1 & 1 & 1 & 2 & 3 \\
Difference, \% & 9 & 6 & 8 & 2 & 1 & 2 & 2 & 4 & 6 \\
\hline
\end{tabular}

At all points of measurement, the level of noise differed from the model by maximum $5 \mathrm{dBA}$, i.e. $1-10 \%$. In many cases, the higher level of noise was obtained when measuring under natural conditions than in simulations. Noise simulation programme does not take into account all conditions, such as the noise from the street or from the neighbours. All these results in the higher level of noise under natural conditions than in the model. 


\section{Conclusions}

1. The dispersion of noise in the rooms was assessed using the simulation programme CadnaA. The dispersion of noise was observed in two models: residential apartment of two rooms and a hairdresser's salon with three working places.

2. In a two-room residential apartment, where two domestic appliances are operating at the same time with the frequency of $500 \mathrm{~Hz}$ the level of noise variates between $50 \mathrm{dBA}$ (in the kitchen and the hallway) and $70 \mathrm{dBA}$ (in the living room, where the noisier device is operating). In the bedroom, the level of noise variates between $48 \mathrm{dBA}$ and $55 \mathrm{dBA}$, except for the space right next to the second source of noise, where the level of noise is significantly higher.

3. In the hairdresser's salon, where two hairdryers and one safety razor are operating at the same time with the frequency of $500 \mathrm{~Hz}$, the level of noise variates between $47 \mathrm{dBA}$ and $55 \mathrm{dBA}$ in the space, where the customers are waiting.

4. With the frequencies of $500 \mathrm{~Hz}$ and $4 \mathrm{kHz}$, the levels of noise in the models are quite similar. The same source of noise in these frequency bands emits the similar levels of noise. With the frequency of $63 \mathrm{~Hz}$, the level of noise decreases significantly, since SON1 and SON2 emit less noise in a low frequency band.

5. The level of noise that is harmful to health starts at $60 \mathrm{dBA}$. This level is exceeded in the first model. Prolonged exposure to such noise may have a negative effect on health.

6. The simulation programme CadnaA is suitable for simulating the dispersion of noise in the rooms. Natural measurements were taken in the apartment equivalent to the model created by the CadnaA programme using the meteranalyser of noise level Bruel\&Kjaer 2260 Investigator. The simulation results differ from natural measurements by $1-10 \%$. The higher level of noise under natural conditions is determined by secondary sources of noise.

\section{References}

[1] American Speech-Language-Hearing Association [online]. 2011. Cited 24 August 2011. Available from internet: http://www.asha.org/uploadedFiles/AIS-Home-Community-Recreational-Noise.pdf

[2] Dries, J. 2009. Understanding, Analyzing and Reducing Ap-pliance Noise [online]. Cited 30 March 2011. Available from internet: www.driesengineering.com

[3] Grubliauskas, R. 2009. Aplinkos triukšmo ir jo mažinimo, taikant lengvas konstrukcijas, tyrimai bei skaitinis modeliavimas [Research and digital modellling of environmental noise and its reduction by applying light structures]. Vilnius: Technika. $138 \mathrm{p}$.

[4] Yijun, L., et al. 2012. Virtual Reality Platform Based Simulation System of Environmental Noise Abatement Research, Physics Procedia 24(2012): 838-844. http://dx.doi.org/10.1016/j.phpro.2012.02.126

[5] LST ISO 1996-2:2008. Akustika. Aplinkos triukšmo aprašymas, matavimas ir ịvertinimas. 2 dalis. Aplinkos triukšmo lygių nustatymas [Acoustics Description, measurement and assessment of environmental noise - Part 2: Determination of environmental noise levels]. $36 \mathrm{p}$.

[6] Nelson, D. I., et al. 2005. The global burden of occupational noise - induced hearing loss, American journal of industrial medicine 48: 446-458. http://dx.doi.org/10.1002/ajim.20223

[7] Petraitis, E. 2010. Skaitinis modeliavimas aplinkos apsaugoje. Vilnius: Technika. 162 p. http://dx.doi.org/10.3846/1118-S

[8] Rahmani, S.; Mousavi, S. M.; Kamali, M. J. 2010. Modeling of road-traffic noise with the use of genetic algorithm, Applied Soft Computing 11(2011): 1008-1013. http://dx.doi.org/10.1016/j.asoc.2010.01.022

[9] Ver, I. L.; Beranek, L. L. 2006. Noise and vibration control engineering.Principles and Applications. Second edition. USA: Copyright. 966 p.

[10] World Health Organization. Burden of disease from environmental noise. Quantification of healthy life years lost in Europe [online]. 2011. Cited 4 March 2012. Available from internet: http://www.euro.who.int/_ data/assets/pdf file/0008/136466/e94888. pdf 